\title{
NMEP based Gaussian Mutation Process on Optimizing Fitness Function for MOEED
}

\author{
M. R. M. Ridzuan ${ }^{\# 1}$, E. E. Hassan ${ }^{\# 2}$, A. R. Abdullah ${ }^{\# 3}$, N. Bahaman ${ }^{* 4}$, A. F. A. Kadir ${ }^{\# 5}$ \\ ${ }^{*}$ Center for Robotics and Industrial Automation (CeRIA), Faculty of Electrical Engineering, Universiti Teknikal Malaysia Melaka, Hang \\ Tuah Jaya, Durian Tunggal, 76100, Malaysia \\ E-mail: ${ }^{1}$ mohamadradzi1992@gmail.com, ${ }^{2}$ erwani@utem.edu.my, ${ }^{3}$ abdulr@utem.edu.my, ${ }^{5}$ fazliana@utem.edu.my
}

\begin{abstract}
* Department of Computer System and Communication, Faculty of Information and Communication Technology, Universiti Teknikal Malaysia Melaka, Hang Tuah Jaya, Durian Tunggal, 76100, Malaysia
\end{abstract}

E-mail: ${ }^{4}$ nazrulazhar@utem.edu.my

\begin{abstract}
The increment of Economic Dispatch (ED) problem is very distressing today. In view of countless of the researchers doing the research to minimize the ED problem day after day, the multi objective New Meta Heuristic Evolutionary Programming (NMEP) techniques are proposed to optimize the multi objective function in ED problem called as Multi Objective Environmental Economic Dispatch (MOEED). The techniques mimic the original Meta Heuristic Evolutionary Programming (Meta-EP) and merge with Artificial Immune System (AIS) with some improvement in Gaussian mutation process and cloning process. The NMEP produced two objective function result simultaneously by exercising the weighted sum method. In order to justify the result, the comparison between the NMEP and Meta-EP techniques is conducted with difference case number of alpha. Therefore, the outcome of the simulation shows the NMEP approach is better than Meta-EP in the both case numbers of alpha. The simulation is operated using MATLAB simulation based on standard IEEE 26 bus system in the laboratory.
\end{abstract}

Keywords - economic dispatch; artificial intelligence; multi objective function.

\section{INTRODUCTION}

Economic dispatch optimization is related to generating the electrical power. In this world, there are many types of electricity sources such as hydro, wind, solar, thermal, tidal energy and nuclear but the major electricity is generated from the thermal plants such as fuel generator [1]. Therefore, Secure Environmental Economic Dispatch (SEED) is studying past a decade to improve the optimization the consequence of electricity utility year after year by priority to the thermal generated. The traditional economic dispatch optimization algorithm proposed, like Linear Programming (LP), Non-Linear Programming (NLP), Lambed Iteration (LI), Lagrangian Relaxation (LR), and Quadratic Programming Algorithm (QP) so as to solve the problem in the beginning but it failed to achieve the large scale problem solution [2]. Nowadays, Artificial Intelligent family (AI) is the famous algorithm to solve the problem through the hundreds of algorithms in the world. Since AI is proposed, there are thousand algorithm dawns based on AI algorithm rules and beginning the modern algorithm due to the recent environmental considerations such as Genetic Algorithm
(GA), Artificial Neural Network (ANN), Simulated Annealing (SA), Tabu Search (TS), Particle Swarm Optimization (PSO), Ant Colony Optimization (ACO), Evolutionary Programming (EP) and Artificial Immune System Algorithm (AIS) [3]-[5]. Evolutionary Programming (EP) is introduced by Lawrence J. Fogel in 1960 through the interest in stochastic optimization strategy [6]. Later in 1986, Meta Heuristic Evolutionary Programming (Meta-EP) is proposed by Glover by using higher level language to improve the optimization problem result [7]. On the other hand, the Meta-EP is the most common algorithm that successfully solves many problems related to the economic dispatch problem. Recently, Meta-EP is a very efficient method and faster than other methods in computational time. The Meta-EP involve two major parts namely as an intensification and diversification [8]. The intensification describes the ability through each optimization stage detail and outcome with high quality solutions, whereas the diversification describes the ability through plenty of dissimilar region of the exploration gap.

Hence, the New Meta Heuristic Evolutionary Programming (NMEP) is inspired by Meta-EP behaviour 
with modification in Gaussian mutation process and added some minor process which is cloning process, adapted from the Artificial Immune System algorithm. The AIS was proposed by Jerne in 1974 [9] and improved in 1990s as a new branch in computational intelligence [10]. The solution generates from the multi objective function technique. The multi objective function problem with a combination of two objectives which is total system loss and total generation cost to minimize both simultaneously by following the condition of constraints [11]. Then, the process of weighted sum techniques combines the objective function to produce the total fitness result [12]. Commonly, the multi objective method required longer computational time and multiple runs than single objective function to obtain the result. In this paper NMEP method has been proposed to solve multi objective economic dispatch problem or MOEED with the effect of optimizing through the elitist approaches multi objective function with the difference type number of alpha based on standard IEEE 26 bus system [13].

\section{MATERIAL AND METHOD}

\section{A. Objective Function}

The multi objective function will be produced from a combination of two or more objective functions into singular objective function representation. Every each multi objective function will combine differential between two or three single objective functions which are total generation cost, total emission and total system loss. Therefore, this paper involved merely in total generation cost and total system loss. The combination of single objective function detail will be discussed in the next section. The formula of each single objective function and constraint is shown below [14]-[15].

1) Multi objection function: In order to discover the maximum fitness function result from two objective function results simultaneously, equation (1) is used to present the objective function known as multi objective function.

$$
\begin{gathered}
F_{T}=\sum_{i=1}^{k}\left(\alpha_{i} \times f_{n i}\right) \\
\sum_{i=1}^{k} \alpha_{i}=1 \quad \text { and } \quad f_{n i}=\frac{\max \left(f_{i}\right)-f_{i}}{\max \left(f_{i}\right)-\min \left(f_{i}\right)}
\end{gathered}
$$

Where, $k$ is a number of objective functions (in this study, $k$ equal to two), $\alpha_{i}$ is weighting factor for $i^{\text {th }}$ the objective function, and $f_{n i}$ is a normalized value for $i^{\text {th }}$ the objective function.

2) Total Generation Cost Minimization: The determined by minimizing the total generation cost is the main priority for this research by following equation (2).

$$
\begin{gathered}
C_{i}\left(P_{g i}\right)=\alpha_{i}+b_{i} P_{g i}+c_{i} P_{g i}{ }^{2} \\
C_{\text {Total }}=\sum_{i=1}^{N g} C_{i}\left(P_{g i}\right) \quad \text { dollar per hour }(\$ / \mathrm{h})
\end{gathered}
$$

Where, is $C_{i}\left(P_{g i}\right)$ the cost of generation for unit $i, P_{g i}$ is the power generated by unit $i$, is the $\alpha_{i}, b_{i}, c_{i}$ cost coefficient for the unit $i$, and $C_{\text {Total }}$ is the sum function of each generating unit $N_{g}$.
3) Total System Loss Minimization: Nowadays, the important objective function of ED is to obtain the entire minimum losses during power system operation identified to be a total system loss minimization. This objective function is presented in the mathematical formulation as in equation (3).

$$
T_{\text {loss }}=\sum_{i=1}^{N_{g}} P_{g i}-P_{\text {load }} \text { Watt per hour (MW/h) }
$$

Where, $T_{\text {loss }}$ is the sum of losses in system demand, $P_{g i}$ is the power generated by unit $i$ and $P_{\text {load }}$ is the sum of load in system demand.

\section{B. Constraints}

The two main equations (4) and (5) is necessary involve to set the limitation of constraint before the total cost minimization process is conducted.

\section{1) Equality constraint formula:}

$$
\sum_{i=1}^{N_{g}} P_{g i}=P_{\text {load }}+T_{\text {loss }}
$$

Where, $P_{\text {load }}$ is system load demand and $T_{\text {loss }}$ is total system losses.

2) Inequality constraint formula:

$$
P_{\min } \leq P_{g i} \leq P_{\max }
$$

0.95 p.u $\leq \mathrm{V} \leq 1.05$ p.u ( for 26 and 57 bus system )

Where, $P_{\min }$ is the minimum real power generation of unit $i$ and $P_{\text {min }}$ is the maximum real power generation of unit $i$.

\section{A New Meta Heuristic Evolutionary Programming Algorithm (NMEP)}

The fundamental of NMEP is the combination between Meta-EP algorithm and AIS algorithm with some modification to improve the original algorithm and produce the better result of the objective function. The differences from the other algorithm are the modification occurring in the Gaussian mutation process and the cloning process will be attached to minimize the total system loss and total generation cost. This approach will be dealing with two different type numbers of alpha which is fixed value and a random value. Every each of algorithm will be simulated through the both type numbers of alpha and the result will be compared to determine the best solution for the economic dispatch problem. This algorithm is conducted in the laboratory by using MATLAB simulation based on standard IEEE 26 bus system.

The multi objective function involved 6 control generator units in order to optimize the result of the combination of total system loss and total generation cost. Naturally, the main process of NMEP is initialization, fitness, mutation, cloning and selection process to obtain the result founded in reference [16]. However, some minor process will be added to improve the result of an algorithm in the initialization process and the Gaussian mutation process will make this algorithm rare from the other. The flow chart of the whole process NMEP algorithm will be shown in Fig. 1. The main and additional process will be discussed in detail below. 


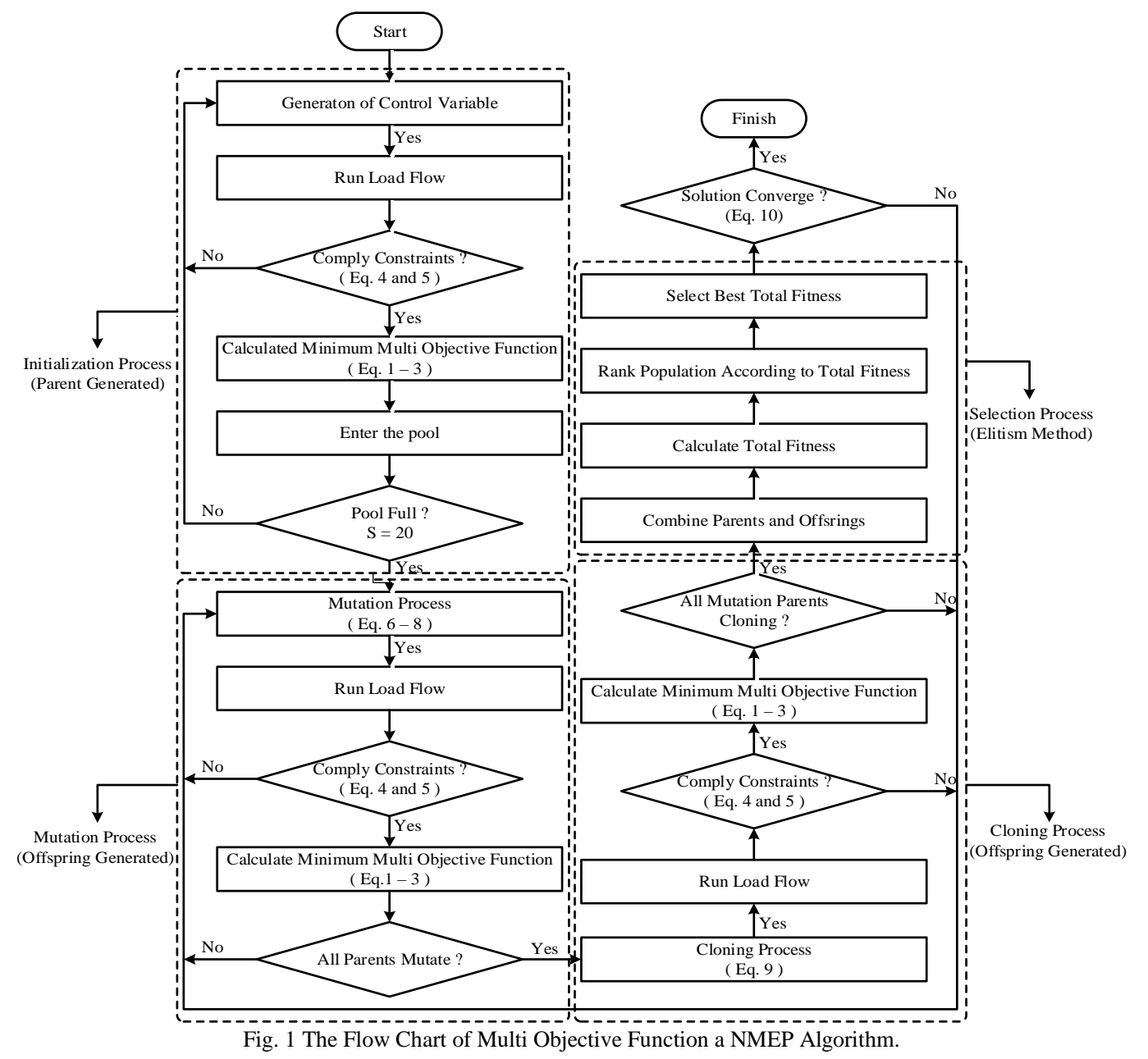

The primary process in NMEP is initialization process. The process practically generated the random number and depended on amount number of population by following the constraints condition in equation (4) and (5). The number of the population commonly is a set of 20 random numbers. In the MATLAB simulation, the number of each control generator will be replaced with $\mathrm{Pg} 1, \mathrm{Pg} 2, \mathrm{Pg} 3, \mathrm{Pg} 4, \mathrm{Pg} 5$ and Pg26 to optimize the multi objective function. The total fitness in multi objective function definitely ( 0 to 1$)$ will cause a new process like finding a number of alpha before evaluation process. The sum number of alpha must equal to 1 at any condition to prevent improper result in finding a number of alpha process. Otherwise, the both numbers of alpha for multi objective function are set to 0.5 in the fixed number of alpha condition.

The evaluation process is the first process to produce the result of fitness or known as multi objective function. The load flow is conducted in order to obtain the result of minimization of total system losses, total generation cost and total emission. The fitness will compute the total system losses and total generation cost, but only observe the total emission. The total fitness calculated is based on the weighted sum process according to equations (1) but to produce the objective function result need follow equation (2) and (3). Then, every objective function will transform into (0 until 1) makes the result easily analyzed.
Then, the mutation process is the different main process from the previous algorithm because some minor modification process was conducted in the Gaussian mutation process. The mutation process is producing a new generation or known as offspring by using equation (6) to (8).

$$
\begin{gathered}
\eta_{i, j}^{\prime}=\eta_{i, j} \exp \left(\tau{ }^{\prime} N(0,1)+\tau N(0,1)\right) \\
L_{i, j}^{\prime}=L_{i, j}+\eta_{i, j}^{\prime}\left(N_{j}(0,1)\right) \\
L_{o i, j}^{\prime}=L_{o i, j}+\eta_{i, j}^{\prime}\left(N_{j}(0,1)\right)
\end{gathered}
$$

Where,

$$
\begin{gathered}
\tau=\sqrt{\frac{1}{\sqrt{2 n}}} \\
\tau^{\prime}=\frac{1}{\sqrt{2 n}}
\end{gathered}
$$

Where, $L_{i, j}, L_{o i, j}, N_{i, j}$ and $\eta_{i, j}^{\prime}$ are $i^{\text {th }}$ components of the respective vectors, $N(0,1)$ is a normally distribution one dimensional random number with mean 0 and $1, N_{j}(0,1)$ indicates the new random number for each value of $j$.

Other than mutation process, the cloning process is a new process in EP to duplicate and produce more fitness result to be selected. The process will be executed by using equation (9) depend on offspring generated result.

$$
\text { Clone }=\text { repmat }(A,[a, b])
$$

Where, $A$ is fitness to be cloned, $a$ clones the row of fitness and $b$ clones the column of fitness. 
The selection process occurs in the last algorithm process. The selection process exploits as a combination between fitness and new offspring result. After the tournament process, 10 best random results were selected. The selection process is most important in producing the final result for the fitness. The result will be ranked from top to lower total fitness in this process.

In the meantime, some condition must be filled before generating the total fitness result. The differences between minimum fitness and maximum fitness should be equal or less than 0.0001 in the convergence test as the following equation (10). While, if the convergence test cannot accomplish, the Gaussian mutation process, cloning process and selection process should be repeated until fulfilling the convergence condition.

maximum $_{\mathrm{fitness}}-$ minimum $_{\mathrm{fitness}} \leq 0.0001$

\section{RESULT AND DISCUSSION}

The six units of control generator were replaced with Pg2, $\mathrm{Pg} 3, \mathrm{Pg} 4, \mathrm{Pg} 5$ and $\mathrm{Pg} 26$ respectively to optimize the multi objective functions in solving economic dispatch problem in this simulation. This simulation will be divided into four different cases and tests with MATLAB simulation based on standard IEEE 26 bus system. In each test cases, 10 independent runs were conducted. Then, some precaution has been taken to prevent the error of result by determining the suitable fixed parameter to run the simulation in each algorithm. Table 1 represents the common parameter applied into each algorithm to justify the NMEP algorithm is better than other algorithms. Besides, each of the parameters chooses from a combination of several common papers. The population size is 20 and the mutation probabilities is 0.0001 for the accuracy of the result. The result is involving common constraints to secure the solution result.

Other than that, the Meta-EP and AIS technique strategy according to researchers in [17] has been merged in order to show the quality of NMEP performance to optimize fitness function of MOEED in the overall result. Thus, the result of the NMEP is able to trustworthiness based on the comparison result with Meta-EP and AIS technique. Furthermore, the result has been convincing after NMEP technique has ability to run the MATLAB simulation in two special cases with is fixed and random number of after applied weighted sum method on two objective functions. In the fixed number of alpha, the 0.5 is applied to total system loss and total generation cost for each technique. Where, the random number of alpha is auto generated during the process until performing the criterion formula for the a total number of alpha in the final stage must equal to 1.0. The result was divided into three categories which is fixed number of alpha, random number of alpha and comparison between both numbers of alpha cases has been explained in detail below. Hence, every objective function and observation condition solution result shown in each table for comparison scenario between NMEP, Meta-EP and AIS technique below.

Table 2 shows the comparison result of a multi objective function in a fixed number alpha condition between NMEP, Meta-EP algorithm and AIS algorithm. Based on the table, the result of the total fitness NMEP algorithm is exactly 1.00000 and better than Meta-EP algorithm with difference about 0.014710 and AIS about 0.016184 . The best fitness result for NMEP, Meta-EP and AIS in total system loss term are $12.26575 \mathrm{MW} / \mathrm{h}, 12.55970 \mathrm{MW} / \mathrm{h}$ and $12.55103 \mathrm{MW} / \mathrm{h}$ respectively while in total generation cost will appear in $15503.62 \$ / \mathrm{h}, 15565.30 \$ / \mathrm{h}$ and $15567.55 \$ / \mathrm{h}$ respectively when according to the greatest total fitness. The total system loss in NMEP algorithm shows better $0.29395 \mathrm{MW} / \mathrm{h}$ from Meta-EP algorithm and $0.28528 \mathrm{MW} / \mathrm{h}$ from AIS in order to minimize the losses. In the meantime, the total generation cost of NMEP technique presents surprising results in decreasing 61.68 dollars/h from the Meta-EP and 63.93 dollars/h from the AIS technique. The result is simulated by using MATLAB simulation based on standard IEEE 26 bus system.

The comparison result of a multi objective function in a random number alpha condition between NMEP, Meta-EP algorithm and AIS algorithm is shown in Table 3. The result of total system loss in NMEP techniques is different within $1.687829 \mathrm{MW} / \mathrm{h}$, whereas total system loss to provide 1052.11 dollars/h differently from the first run until the tenth run of MATLAB simulation. The total fitness result of NMEP technique is 0.003671 better than Meta-EP and 0.003671 better than AIS technique. This is because the fitness through some modification in Gaussian mutation process and the cloning process. Then, the comparison total system loss of NMEP result between Meta-EP and AIS approach shows that it can reduce the cost about 4663.55 dollars per year and 3766.47 dollars per year (if charge 0.26 cents $=1 \mathrm{~kW} / \mathrm{h}$ ). Other than that, the total generation cost decreased about 153037.20 dollars per year and 11563.20 dollars per year after using NMEP technique compared to Meta-EP and AIS respectively. An improvement of total fitness NMEP technique is the main objective of this simulation that performs 0.00367 better than Meta-EP and 0.00666 better than AIS technique. Last but not least, the NMEP approach is much faster for completing the task through the 10 times run from MATLAB simulation compared Meta-EP technique.

TABLE I

The PARAmeter Used To Produce the Result FOR STANDARd IEEE 26 Bus System

\begin{tabular}{|c|c|c|c|c|c|c|c|c|c|c|}
\hline \multirow{2}{*}{$\begin{array}{c}\text { No. of } \\
\text { Generator }\end{array}$} & \multicolumn{3}{|c|}{ Cost Coefficients } & \multicolumn{1}{c|}{ MV Limit } & \multicolumn{4}{c|}{ Emission coefficient } \\
\cline { 2 - 12 } & $\boldsymbol{\alpha}_{\boldsymbol{i}}$ & $\boldsymbol{b}_{\boldsymbol{i}}$ & $\boldsymbol{c}_{\boldsymbol{i}}$ & Min & Max & $\boldsymbol{\alpha}$ & $\boldsymbol{\beta}$ & $\boldsymbol{\gamma}$ & $\boldsymbol{\varepsilon}$ & $\boldsymbol{\Lambda}$ \\
\hline 1 & 240 & 7.0 & 0.0070 & 100 & 500 & 4.091 & -5.543 & 6.490 & $2.0 \mathrm{e}-4$ & 2.857 \\
\hline 2 & 200 & 10.0 & 0.0095 & 50 & 200 & 2.543 & -6.047 & 5.638 & $5.0 \mathrm{e}-4$ & 3.333 \\
\hline 3 & 220 & 8.5 & 0.0090 & 80 & 300 & 4.258 & -5.094 & 4.586 & $1.0 \mathrm{e}-6$ & 8.000 \\
\hline 4 & 200 & 11.0 & 0.0090 & 50 & 150 & 5.326 & -3.550 & 3.380 & $2.0 \mathrm{e}-3$ & 2.000 \\
\hline 5 & 220 & 10.5 & 0.0080 & 50 & 200 & 4.258 & -5.094 & 4.586 & $1.0 \mathrm{e}-6$ & 8.000 \\
\hline 26 & 190 & 12.0 & 0.0075 & 50 & 120 & 6.131 & -5.555 & 5.151 & $1.0 \mathrm{e}-5$ & 6.667 \\
\hline
\end{tabular}


TABLE II

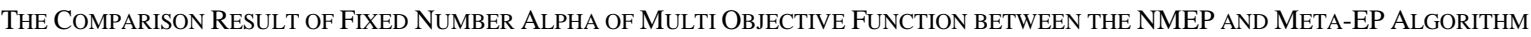

\begin{tabular}{|c|c|c|c|c|c|c|c|c|}
\hline \multicolumn{3}{|c|}{ NMEP } & \multicolumn{3}{|c|}{ Meta-EP } & \multicolumn{3}{|c|}{ AIS } \\
\hline $\begin{array}{c}\text { Total } \\
\text { System } \\
\text { Loss } \\
(\mathbf{M W} / \mathrm{h}) \\
\end{array}$ & $\begin{array}{c}\text { Total } \\
\text { Generation } \\
\text { Cost }(\$ / h)\end{array}$ & Fitness & $\begin{array}{c}\text { Total } \\
\text { System } \\
\text { Loss } \\
(\mathrm{MW} / \mathrm{h}) \\
\end{array}$ & $\begin{array}{c}\text { Total } \\
\text { Generation } \\
\text { Cost }(\$ / h)\end{array}$ & Fitness & $\begin{array}{c}\text { Total } \\
\text { System } \\
\text { Loss } \\
(\mathrm{MW} / \mathrm{h}) \\
\end{array}$ & $\begin{array}{c}\text { Total } \\
\text { Generation } \\
\text { Cost }(\$ / h)\end{array}$ & Fitness \\
\hline 12.265746 & 15503.62 & 1.000000 & 12.559700 & 15565.30 & 0.985290 & 12.551028 & 15567.55 & 0.983816 \\
\hline 12.262093 & 15488.17 & 1.000000 & 12.175869 & 15563.95 & 0.983263 & 12.760585 & 15529.70 & 0.982562 \\
\hline 12.446711 & 15524.24 & 1.000000 & 12.884948 & 15522.71 & 0.982558 & 12.367573 & 15590.93 & 0.981357 \\
\hline 12.367573 & 15590.93 & 0.989945 & 12.668318 & 15518.12 & 0.979829 & 12.469544 & 15591.87 & 0.975144 \\
\hline 12.367573 & 15590.93 & 0.989945 & 12.390375 & 15622.69 & 0.979289 & 12.343600 & 15619.54 & 0.971598 \\
\hline 12.367573 & 15590.93 & 0.989945 & 13.134339 & 15478.23 & 0.975731 & 12.825272 & 15591.02 & 0.969711 \\
\hline 12.377280 & 15562.57 & 0.975833 & 12.535108 & 15572.34 & 0.970070 & 12.841781 & 15512.71 & 0.969612 \\
\hline 12.376458 & 15622.51 & 0.960560 & 12.742709 & 15563.74 & 0.966027 & 12.418475 & 15558.51 & 0.967433 \\
\hline 12.368048 & 15611.08 & 0.951975 & 12.485956 & 15490.14 & 0.964331 & 12.646618 & 15543.71 & 0.962623 \\
\hline 12.180671 & 15557.12 & 0.949149 & 12.559700 & 15529.72 & 0.964316 & 12.667720 & 15650.98 & 0.952903 \\
\hline \multicolumn{3}{|c|}{ Average Time : 22.354 minutes } & \multicolumn{3}{|c|}{ Average Time : 29.928 minutes } & \multicolumn{3}{|c|}{ Average Time : 22.355 minutes } \\
\hline
\end{tabular}

TABLE III

The Comparison Result of Random Number Alpha of Multi ObJective Function BetweEn the NMEP and Meta-EP Algorithm

\begin{tabular}{|c|c|c|c|c|c|c|c|c|}
\hline \multicolumn{3}{|c|}{ NMEP } & \multicolumn{3}{|c|}{ Meta-EP } & \multicolumn{3}{|c|}{ AIS } \\
\hline $\begin{array}{c}\text { Total } \\
\text { System } \\
\text { Loss } \\
(\mathrm{MW} / \mathrm{h})\end{array}$ & $\begin{array}{c}\text { Total } \\
\text { Generation } \\
\text { Cost }(\$ / \mathbf{h})\end{array}$ & Fitness & $\begin{array}{c}\text { Total } \\
\text { System } \\
\text { Loss } \\
(\mathrm{MW} / \mathrm{h})\end{array}$ & $\begin{array}{c}\text { Total } \\
\text { Generation } \\
\text { Cost }(\$ / h)\end{array}$ & Fitness & $\begin{array}{c}\text { Total } \\
\text { System } \\
\text { Loss } \\
(\mathrm{MW} / \mathrm{h})\end{array}$ & $\begin{array}{c}\text { Total } \\
\text { Generation } \\
\text { Cost }(\$ / h)\end{array}$ & Fitness \\
\hline 12.364651 & 15538.65 & 1.000000 & 12.569408 & 15556.12 & 0.996329 & 12.530021 & 15539.97 & 0.993341 \\
\hline 12.125512 & 15559.19 & 0.990317 & 13.461909 & 15473.11 & 0.996215 & 13.028713 & 15570.67 & 0.992323 \\
\hline 12.104303 & 15578.08 & 0.989763 & 12.876567 & 15502.85 & 0.994561 & 13.205123 & 15581.71 & 0.986905 \\
\hline 13.394688 & 12672.91 & 0.987124 & 13.707969 & 15493.12 & 0.991180 & 12.243059 & 15545.44 & 0.986529 \\
\hline 15.123901 & 15401.96 & 0.986374 & 12.933634 & 15486.71 & 0.986522 & 12.359122 & 15547.63 & 0.986360 \\
\hline 14.464318 & 14494.20 & 0.978512 & 12.376899 & 15559.90 & 0.984977 & 12.915493 & 15508.11 & 0.985820 \\
\hline 12.783565 & 15492.93 & 0.974442 & 12.585103 & 15471.31 & 0.980633 & 12.584968 & 15546.00 & 0.981810 \\
\hline 13.341803 & 15538.91 & 0.972558 & 13.214646 & 15502.65 & 0.977933 & 12.486224 & 15666.57 & 0.975277 \\
\hline 12.241509 & 15601.25 & 0.960652 & 13.845380 & 15545.56 & 0.977632 & 12.349834 & 15594.31 & 0.966014 \\
\hline 14.063480 & 14486.54 & 0.948254 & 12.420245 & 15556.12 & 0.972501 & 12.706467 & 15564.28 & 0.964427 \\
\hline \multicolumn{3}{|c|}{ Average Time : 30.773 minutes } & \multicolumn{3}{|c|}{ Average Time : 34.523 minutes } & \multicolumn{3}{|c|}{ Average Time : $\mathbf{3 1 . 4 5 2}$ minutes } \\
\hline
\end{tabular}

TABLE IV

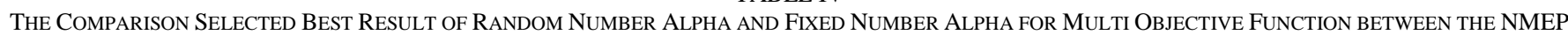
AND META-EP ALGORITHM

\begin{tabular}{|c|c|cccc|}
\hline $\begin{array}{c}\text { No. of } \\
\text { Alpha }\end{array}$ & Algorithm & $\begin{array}{c}\text { ( Fitness) } \\
\text { Total System Losses } \\
(\mathbf{M W} / \mathbf{h})\end{array}$ & $\begin{array}{c}\text { ( Fitness) } \\
\text { Total Generation Cost } \\
(\mathbf{\$} / \mathbf{h})\end{array}$ & $\begin{array}{c}\text { (Observation) } \\
\text { Total Emission } \\
(\text { ton/h) }\end{array}$ & $\begin{array}{c}\text { ( Fitness) } \\
\text { Fitness }\end{array}$ \\
\hline \multirow{3}{*}{ Fixed } & NMEP & $\mathbf{1 2 . 2 6 5 7 4 6}$ & $\mathbf{1 5 5 0 3 . 6 2}$ & $\mathbf{1 8 6 8 5 . 1 6}$ & $\mathbf{1 . 0 0 0 0 0 0}$ \\
& META-EP & 12.559700 & 15565.30 & 21353.37 & 0.985290 \\
& AIS & 12.551028 & 15567.55 & 22487.54 & 0.983816 \\
\multirow{3}{*}{ Random } & NMEP & $\mathbf{1 2 . 3 6 4 6 5 1}$ & $\mathbf{1 5 5 3 8 . 6 5}$ & $\mathbf{2 2 1 1 1 . 1 1}$ & 17904.13 \\
& META-EP & 12.569408 & 15556.12 & 17494.92 & 0.996329 \\
& AIS & 12.530021 & 15539.97 & 0.993341 \\
\hline
\end{tabular}

Table 4 shows the comparison selecting the best results of random number alpha and fixed number alpha for multi objective function between the NMEP, Meta-EP and AIS algorithm. Besides, despite the main multi objective function and total fitness, the total emission is attached in the final simulation to observe the emission level without distracting any objective function. Since the focused of the simulation is the difference between fixed and random number of alpha, hence each best result is collected to determine result differences. Thus, by using the weighted sum method, the fitness will appear after the combination between total system loss and total generation cost for the both fixed and random number of alpha. In the meantime, the real final value of both objective functions will display to compare with Meta-EP and AIS. The solution of the problem is determined based on the fitness value for each involving technique. Before that, the result has been discussing the comparison between each objective function and total emission on observation condition. 
First, the fixed number of alpha has discussed. The total system loss of NMEP reduces the losses about 2575.04 MW per year than Meta-EP and 2499.07 MW per year than AIS. Likewise, the important part for each generator is the total generation cost of NMEP saving the cash about 526993.92 dollar per year from Meta-EP and 560026.80 dollar per year from AIS. Beyond the result, the observation of total emission of NMEP shows impressively after generator release the clean air pollution about 23373519.60 ton per year than Meta-EP and 33308848.80 ton per year than AIS. Moreover, the NMEP win the fitness value about 0.014710 than Meta-EP and 0.016184 than AIS technique.

The second though, the random number of alpha was explained in order to understand the differences between comparative techniques. Again, the total system loss of NMEP appears to be the best technique to reduce the losses about 1793.67 MW per year than Meta-EP and 1448.64 MW per year than AIS. Also in total generation cost, the NMEP technique economy than Meta-EP about 153037.20 dollar per year and from AIS about dollar per year. On the observation condition, the NMEP emission for a random number of alpha produce more air pollution about 4206.98 ton per hour than Meta-EP and 4616.19 ton per hour from AIS. However, the worst result appears on observation and not even a little bit distracted the objective function. The NMEP completes the solution after involved about 0.003671 than Meta-EP and 0.006659 than AIS on fitness function which is the main result of this paper.

In addition, the both types of alpha have been discussed to provide comparative result clearly. Therefore, the total system losses will appear about $0.1045545 \mathrm{MW} / \mathrm{h}$ average differences between fixed and random number of alpha. Next, total generation cost produced approximately 43.41 dollars per hour average differences after comparing NMEP Meta-EP and AIS technique in both numbers of alpha. After that, the comparison between fixed and random number of alpha in case total emission is developed to about 1176.29 tons per hour average differences while the result of total fitness is only 0.010282 in average differences. As mentioned before, the NMEP algorithm is better than MetaEP and AIS algorithm even though the best result is selected in each fitness in the MATLAB simulation. Last but not least, although the NMEP only taken less a few minutes computational time compared to other selected methods in completing the task that justifies this method achieves the best approach in optimizing the fitness for MOEED from every angle.

\section{CONCLUSION}

An elitist multi objective function artificial intelligence known as a New Meta Heuristic Evolutionary Programming (NMEP) has been proposed for solving the Secured Environmental Economic Dispatch problem for this research. Then, the NMEP techniques produced the result by combined the single objective function by using a weighted sum method known as a multi objective function with differences number of alpha cases. From the multi objective function both cases for number of alpha result of NMEP algorithm shows better performances in total system loss and total generation cost compared with Meta-EP and AIS. Other than that, the random number of alpha produces a small value of system losses and less fuel generator cost than a fixed number of alpha. However, the observation of NMEP technique objective function shows less total pollution generated from the generator compared to the Meta-EP and AIS technique on the fixed number of alpha whereas worst in a random number of alpha. However, the main objective function in this paper successful solving the EED problem on the power plants distribution. Therefore, the achievement of all performances that conclude the NMEP algorithm can develop better solutions for the economic dispatch problem than another algorithm.

\section{NOMENCLATURE}

$\begin{array}{ll}\text { \$/h } & \text { Dollar Per Hour } \\ \text { ACO } & \text { Ant Colony Optimization } \\ \text { AI } & \text { Artificial Intelligent } \\ \text { AIS } & \text { Artificial Immune System } \\ \text { ANN } & \text { Artificial Neural Network } \\ \text { ED } & \text { Economic Dispatch } \\ \text { EP } & \text { Evolutionary Programming } \\ \text { GA } & \text { Genetic Algorithm } \\ \text { LI } & \text { Lambed Iteration } \\ \text { LP } & \text { Linear Programming } \\ \text { LR } & \text { Lagrangian Relaxation } \\ \text { Meta-EP } & \text { Meta Heuristic Evolutionary Programming } \\ \text { MW/h } & \text { Megawatt Per Hour } \\ \text { NLP } & \text { Non-Linear Programming } \\ \text { NMEP } & \text { New Meta Heuristic Evolutionary Programming } \\ \text { PSO } & \text { Particle Swarm Optimization } \\ \text { QP } & \text { Quadratic Programming Algorithm } \\ \text { SA } & \text { Simulated Annealing } \\ \text { SEED } & \text { Secure Environmental Economic Dispatch } \\ \text { ton/h } & \text { Ton Per Hour } \\ \text { TS } & \text { Tabu Search } \\ \text { Pg } & \text { Power Generator } \\ & \end{array}$

\section{ACKNOWLEDGMENT}

The research is financially supported by the team of this project from Advance Digital Signal Processing Laboratory (ADSP Lab). Special thanks also go to the Faculty of Electrical Engineering of Universiti Teknikal Malaysia Melaka (UTeM) and Ministry of Higher Education Malaysia (MOHE) for giving the cooperation and funding to ensure the feasibility and success of this research namely RAGS/1/2015/TK0/FKE/03/B0094. Their support is gratefully acknowledged.

\section{REFERENCES}

[1] Farhat, I. A., \& El-Hawary, M. E. (2012, April). Multi-objective economic-emission optimal load dispatch using bacterial foraging algorithm. In Electrical \& Computer Engineering (CCECE), 2012 25th IEEE Canadian Conference on (pp. 1-5). IEEE.

[2] Swain, R. K., Sahu, N. C., \& Hota, P. K. (2012). Gravitational search algorithm for optimal economic dispatch. Procedia Technology, 6, 411-419.

[3] Niknam, T., Azizipanah-Abarghooee, R., \& Aghaei, J. (2013). A new modified teaching-learning algorithm for reserve constrained dynamic economic dispatch. IEEE Transactions on power systems, 28(2), 749-763.

[4] Yassin, I. M., Zabidi, A., Ali, M. S. A. M., Tahir, N. M., Abidin, H. Z., \& Rizman, Z. I. (2016). Binary Particle Swarm Optimization Structure Selection of Nonlinear Autoregressive Moving Average with Exogenous Inputs (NARMAX) Model of a Flexible Robot Arm. 
International Journal on Advanced Science, Engineering and Information Technology, 6(5), 630-637.

[5] Dhanalakshmy, D. M., Pranav, P., \& Jeyakumar, G. (2016). A Survey on Adaptation Strategies for Mutation and Crossover Rates of Differential Evolution Algorithm. International Journal on Advanced Science, Engineering and Information Technology, 6(5), 613-623.

[6] Mallipeddi, R., Mallipeddi, S., \& Suganthan, P. N. (2010). Ensemble strategies with adaptive evolutionary programming. Information Sciences, 180(9), 1571-1581.

[7] BoussaïD, I., Lepagnot, J., \& Siarry, P. (2013). A survey on optimization metaheuristics. Information Sciences, 237, 82-117.

[8] Yi, H., Duan, Q., \& Liao, T. W. (2013). Three improved hybrid metaheuristic algorithms for engineering design optimization. Applied Soft Computing, 13(5), 2433-2444.

[9] Dasgupta, D., Ji, Z., \& Gonzalez, F. (2003, December). Artificial immune system (AIS) research in the last five years. In Evolutionary Computation, 2003. CEC'03. The 2003 Congress on (Vol. 1, pp. 123-130). IEEE.

[10] Basu, M. (2012). Artificial immune system for combined heat and power economic dispatch. International Journal of Electrical Power \& Energy Systems, 43(1), 1-5.

[11] Singh, M., \& Dhillon, J. S. (2016). Multiobjective thermal power dispatch using opposition-based greedy heuristic search. International Journal of Electrical Power \& Energy Systems, 82 339-353.
[12] Zhang, R., Zhou, J., Mo, L., Ouyang, S., \& Liao, X. (2013). Economic environmental dispatch using an enhanced multi-objective cultural algorithm. Electric Power Systems Research, 99, 18-29.

[13] King, R. T. A., \& Rughooputh, H. C. (2003, December). Elitist multiobjective evolutionary algorithm for environmental/economic dispatch. In Evolutionary Computation, 2003. CEC'03. The 2003 Congress on (Vol. 2, pp. 1108-1114). IEEE.

[14] Hassan, E. E., Rahman, T. K. A., Zakaria, Z., \& Bahaman, N. (2015). The Improved of BFOA for Ensuring the Sustainable Economic Dispatch. In Applied Mechanics and Materials (Vol. 785, pp. 83-87). Trans Tech Publications.

[15] Yasin, Z. M., Rahman, T. K. A., \& Zakaria, Z. (2012, October) Multiobjective quantum-inspired evolutionary programming for optimal location and sizing of distributed generation. In Sustainable Utilization and Development in Engineering and Technology (STUDENT), 2012 IEEE Conference on (pp. 233-238). IEEE.

[16] Biethahn, J., \& Nissen, V. (Eds.). (2012). Evolutionary algorithms in management applications. Springer Science \& Business Media.

[17] Basu, M. (2011). Artificial immune system for dynamic economic dispatch. International Journal of Electrical Power \& Energy Systems, 33(1), 131-136. 